\title{
The Characteristics of The Gig Economy
}

\author{
Qi Zheng, Weiguo Yang \\ School of Labor and Human Resources \\ Renmin University of China
}

\begin{abstract}
In the industrial era, traditional firms emerged as an efficient resource allocation. In the past two decades, informatization and technological development have spawned a series of emerging economic models, among which the gig economy attracts much attention globally. With the popularity of the Internet, mobile applications, and all other social, economic, political, and cultural changes, traditional mass production is no longer able to adapt to such incredibly fast development, let alone to meet the diversified needs for commodities and service. As a result, the gig economy, as a new mechanism to achieve optimal resource allocation, was born, characterized by the decomposition of jobs, skillization and capitalization of workers, integration of internal and external human capital, and decentralization of corporate management. But there are still problems, as keeping market density while avoiding "blockage", and protecting users' privacy, which need to be seriously considered in future research and policy formulation.

Keywords: The technology development; Gig economy; Resource allocation mechanism; Job decomposition; Management decentralization
\end{abstract}

\section{Introduction}

The information technology era has given rise to various economic models that are different from the traditional industrial economy, resulting in a large number of emerging employment models and their corresponding working relationships. Among them, the Internet-based "gig economy" and its flexible working relation have attracted much attention from all walks of society, because of the increasing number of participants and its considerable growth rate around the world. In Europe, one in two young people between the ages of 15 and 24 choose to engage in the gig economy (McKinsey, 2016a). Drawn from the Ali Research Institute forecast, more than 400 million people are estimated to join the gig economy in China in the next 15 years. Platform enterprises involved in the gig 
economy are diverse (Stefanie, 2016), from space sharing (Airbnb and YardShare), ride sharing (Uber, Didi, and BlaBlaCar), skills-sharing (Craigslist), to e-commerce (Taobao, Amazon, and eBay).

The nature and characteristics of the gig economy are described in government and nongovernmental organizations' work-related research reports, literature, rules and regulations that are done at the national, regional, and global levels, respectively. The review of these data reveal that countries have different understandings about the gig economy. The OECD (2016) and most large countries, such as the United States, the United Kingdom, and Canada, believe that the gig economy is a new type of employment model (Rosen, 2016; Board of Governors of the Federal Reserve System, 2016; Office of Tax Simplification, 2016; Government of Canada, 2016; Texas Workforce Investment Council, 2017; Canada Advisory Council on Economic Growth, 2017). The European Commission believes that the gig economy is a new economy model based on the Internet and information technology (European Commission, 2016). The IMF (2016) proposes that the gig economy is a new business model. Whether at national, regional, or global level, the understanding of the nature of gig economy nature is not absolute. Thereafter, to properly define the gig economy and describe its characteristics, we need to discuss first how the gig economy emerged.

\section{The Origin of the Gig Economy: From Traditional Employment Relations to}

\section{Flexible Working Relations}

In primitive society, fishing and hunting were the main means of production. All members of the workforce needed to do productive work to meet their own needs and that of the aged, the weak, and the sick. However, at that time, people were poor. With the entry of human society into a period of civilization and prosperity, a large number of social members began to participate in social work (Smith, A., 2016) and gathered to form firms. Nevertheless, under the gig economy in the Internet era, traditional firms and formal employment are gradually changing. In the era of the industrial economy, why were traditional enterprises created and what is the nature of traditional firms?

Coase $^{1}$ gave us the answer in The Nature of the Firm (Williamson, O.E., 1993). Traditionally, a firm is a profit-oriented business organization, and to some extent, an aggregation of single individuals. In the traditional theory of classical economics, laborers engaged in production were considered "economic individuals" who were homogeneous, rational, and pursue their own interests.

\footnotetext{
${ }^{1}$ Ronald H. Coase was one of the most innovative economists of the twentieth century. Besides his best known paper titled The Nature of the Firm, he also played a significant role in the development of the field of law and economics, making numerous influential contributions to topics containing public utilities, regulation and the functioning of markets.
} 
In the era of the industrial economy, given that strength of individuals was undoubtedly weak, maximizing their interests on their own efforts was difficult; hence, they tended to unite, which formed a firm. Each producer individually sold their surplus products on the market, and a deal would be reached on the premise of meeting consumers' demand. In the free market economy, the role of the market price mechanism was to achieve optimal allocation of resources. However, due to market uncertainty, government taxation, and other factors, corresponding transaction costs were created (cost of price discovery and negotiation) (Kroszner, R. \& Putterman, L.G., 2015). From the perspective of the entire market, total costs of all individual transaction behaviors were considerably huge. Therefore, to minimize price discovery and negotiation costs, producers congregated, and firms emerged.

Coase believed that firms could be seen as a substitute for price in allocation of resources. Firms internalize a large number of external transaction contracts, thereby greatly reducing transaction costs and realizing the uniform allocation and sale of all their resources and products. As a result, the cost of the price mechanism to identify the relative commodity prices is avoided (Williamson, O.E., 1993). The emergence of firms was also conducive to reducing the inherent uncertainty of the market mechanism, thereby creating the possibility of long-term contracts. $\mathrm{He}$ concluded that the nature of the firm was the effective mechanism for resource allocation in place of price to save transaction costs, which is an aggregation, integrating all aspects of market operation into the firms, as well as organizing and coordinating all links (Williamson, O.E., 1993). Although the role of firms in saving transaction costs is unquestionable, the reason for the creation of firms is not only to reduce transaction costs, but also to save production costs. During the period of industrialized mass production, the demand for "exchange" had led to the social labor division and production specialization. Adam remarked that "the greatest improvement in productivity, skills and judgments in the labor, seem to be the result from labor division" (Adam, S., 2016). The regulation of the labor division required a powerful integration force, which played the key role of gathering individuals who produce homogeneous products together, using scale production to reduce production costs. Firms should not be regarded as substitutes for price mechanism, both of which are dynamic results of market development, where a complementary and long-term co-existing relationship should exist. Given that entrepreneurs' power to control production factors was restricted to the "scope of the contract," the part that exceed the scope of the contract will be subject to market transactions (Williamson, O.E., 1993). Apart from Coase, other scholars explained the reasons for the emergence of firms from different angles. For example, Alchian and Deynseta believed that under technical conditions, ownership and supervision functions were concentrated in the central, compared with unsupervised small scale production, firms had comparative advantages on productivity and revenue sharing (Kroszner, R. \& Putterman, L.G., 2015). They indicated that 
the creation of firms was designed to avoid the high cost of recurring activities.

Coase's understanding of the nature of firms was based on the following premises. First, labor force during the industrial economy era was homogeneous, rational, and economic, and pursued the maximization of individual economic benefits. In the industrialization period, the factory system that espoused the barbaric exploitation of workers was established. Marx's theory of labor value held that the growth in profits of enterprises and employers came from the surplus value generated by the extension of labor time of workers. Moreover, employers regarded labor merely as a production factor, instead of human beings with emotional, social, and democratic needs (Marx, K., 2013).

Second, the underlying context at that time was the gradual specialization of traditional industrial production and labor division. Employers deliberately broke the entire working process down into piece-work to be completed by a number of workmen. The way such individual workers interacted with one another enabled duties to be well performed, thereby greatly improving working efficiency (Adam, S., 2016). Masten claimed that employees' obligations to employers are the core of the firm (Kroszner, R. \& Putterman, L.G., 2015). Market demand was "massive" and "homogeneous;" hence, producers, with the division of labor, pursued large-scale production of homogeneous products.

Third, due to the increasing complexity of division of labor, workers tended to be low-skilled and became "people who have the same or nearly the same simple operation skill throughout their lifetime, neither with the chance to make use of their knowledge nor with the chance to display their own inventions to find out shortcut of eliminating difficulties...inevitably lose the habit of using knowledge, generally become ignorant and benighted...Therefore, workers are specialized in their own work at the expense of brain power, social ability, etc." Moreover, workers were unwilling to supplement their knowledge and to think about other things because of the simplicity and monotony of their careers (Adam, S., 2016).

Fourth, in the industrialization period, information technology had not yet been created, and the cost for individual labor force to use the price mechanism to identify the relative price was considerably high. Under the catalysis of the preconditions above, the firm-a group of individual workmen - has emerged as an alternative to price mechanism to optimize the allocation of resources.

Marx (2013) mentioned in Capital that when the era of capitalist barbaric exploitation ended, the legal wage and working-hours system became popular. Shortened working hours and flexible working systems would also become significant development trends in the future (Marx, K., 2013). With the development of science and technology, as well as changes in the society and the economy, labor relations has undergone tremendous changes. First, workers are no longer regarded as rational economic people who only pursue their own interests, but as complex individuals with social, 
psychological, and democratic needs. Workers do not only meet economic needs, but also their personal needs, such as work and life balance, individual development, corporate and social recognition, and self-value realization. Second, the increasing complexity of division of labor in the industrial age has led to the low-end and homogenization of workers' skills. In contrast, workers in the digital economy era exemplify "skillization," and workers with specific skills are considered scarce resources in the labor market. Third, to adapt to diversified product and service needs, workers often advance their skills or master multiple skills simultaneously. This practice is similar to what Smith said about barbaric society (hunting and nomadic society) in which everyone needed to engage in multiple kinds of work. (Smith, A., 2016). The difference is that "occupations" in primitive society were limited, whereas they are unimaginably diverse in the digital economy era. Fourth, the advent of informatization, the popularity and use of the Internet and information technology in production transactions have greatly reduced the production and transaction costs of workers. Thus, people no longer need to congregate and establish firms simply to produce and trade. Fifth, market demand for products and services is personalized and diversified, rendering traditional useless large-scale production pointless. As a result, the gig economy has emerged as an effective mechanism for realizing efficient resource allocation in the new era.

\section{The Nature and Characteristics of the Gig Economy}

Traditional industrial relations has four distinct characteristics (Williamson, O.E., 1993). First, firms implement job systems. An employer has absolute control over laborers' production process, work schedule, working duration, tasks, and workplace environment. Such extent of control describes the essential feature of the relationship between an employer and an employee in a traditional firm, "which is precisely the right that distinguishes the employee from the ordinary independent contractor." Second, workers are low-skilled and proletarian because they are engaged in simple repetitive production. In addition, the factors of production and materials of production are controlled by an employer. Employees (laborers) are commonly regarded as a "factor of production" with only economic attributes, aiming at maximizing their own interests without social, democratic, and psychological needs (Taylor, F. W., 2013). Third, the internalization of labor dictates that companies use internal labor to produce to save production and transaction costs. Moreover, corporate management is highly hierarchical and bureaucratic. Traditional corporate governance presents a strict "hierarchical, and level-by-level management" (bureaucracy). In the industrial era, hierarchical and bureaucratic management could greatly reduce communication and production costs, resolve labor conflicts, and improve enterprise efficiency.

Uber (China) (Yang, W.G., Zhang, C.G. \& Xin, X.L., 2018) is one of the earliest car-hailing platforms. Any car owner from any location who meets the platform requirements (driving age, vehicle meets a certain age and configuration) is able to register as an Uber driver, who can use the 
mobile application to provide ride sharing services. Uber does not impose mandatory operating hours of registered drivers, that is, drivers can arrange their own schedule.

The complete workflow involves the following steps: passenger orders; platform dispatches; driver provides service; passenger settles payment online; passenger provides service feedback; platform conducts post-service appeal and responsibility judgment. Uber's judgment on driver performance is based on the comprehensive calculation of various indicators, such as length of service, mileage, service evaluation, and appeals. The Uber driver is seen not as an internal employee of the platform, but as an external participant to the platform. Ride sharing drivers are able to freely control their working hours and working locations. Drivers can also provide their own private cars for operation and must meet platform-specific driving age requirements. Uber manages and evaluates its ride sharing drivers through the platform based on the results of drivers' performance. Drawn from the example of Uber (China), platforms in the gig economy are characterized by the decomposition of jobs, skillization and capitalization of workers, integration of internal and external human capital, and decentralization of corporate management.

\subsection{Decomposition of jobs}

Decomposing a job into work is a major transformation in the employment model, as the job system is one of the three basic elements of the traditional employment relationship. Based on the traditional labor contract system, a job is a broad concept that limits the work content, time, place, method, and target of labor, embodying the "right of control" of an enterprise or organization on a laborer. In traditional enterprises, laborers integrating into jobs, each individual is closely linked with a specific job in which the prescribed work should be done. In the gig economy, a job is broken down into many small pieces (work, projects, or tasks) in such a way that "worker-work integration" takes the place of "worker-job integration." "Worker-work integration" refers to the close linkage between workers and certain work, tasks, or projects. Individuals have control over the entire process and results of their own work, with the right of deciding what, when, where, and how to do when working (US Department of Labor, 2019). Therefore, working relations in the gig economy demonstrate flexibility in workplace and work schedule.

Yang Weiguo et al. point out that job decomposition means that traditional job responsibilities are continuously decomposed and pieced into subtle and precise working tasks (Yang, W.G., Zhang, C.G. \& Xin, X.L., 2018). Unlike the fixed salary of the traditional job system, people engaged in the gig economy accumulate wealth by taking on various independent work (McKinsey, 2016) and by acquiring subcontracts for several independent tasks through the Internet (Crowdwork) (Stefanot, 2016). In the industrial era, the completion of work is likened to beads on a timeline (simple repetition, fixed time, and fixed place). Whereas, in the gig economy, work is full of uncertainty, the 
completion of which is like a drawer filled with electronic instruments and wires, where the beginning and the end are no longer clear (Tepper, 2016). Unlike the permanent employment relationship in the traditional job system, independent workers nowadays seek short-term job opportunities (Sanders \& Pattison, 2016), work on a fragmented project or task (Wordsworth et al., 2016), and get paid by completing the work items specified within the limited time period (Frost, 2017) through digital platforms, such as Uber and Airbnb (McKinsey, 2016). Jobs are replaced by specific tasks, and the labor demand side provides temporary working opportunities to independent workers (Sanders \& Pattison, 2016), focusing on work and performance results rather than on attendance. Process factors, such as the working methods, working place, working time of those who participate in the gig economy (hereinafter referred to as "giggers") are no longer important, and the platforms pay more attention to the quality of work output. (Mulcahy, 2017). For instance, giggers find and engage in temporary work or service through mobile applications with specific standards and requirements for output quality (transportation, cleaning, errands) (Stefanot, 2016). As platforms do not control work processes, the most direct result is remote cooperation and flexible working time.

\section{Remote cooperation}

Remote cooperation refers to the spatial separation of labor individuals and organizations; even workers in remote areas can search for and obtain work opportunities through the Internet (Yang, W.G., Zhang, C.G. \& Xin, X.L., 2018). In the gig economy, workers, as independent contractors and freelancers, are engaged in various alternatives to full-time jobs, changing the perception that people associate a job with a fixed workplace (Mulcahy, 2017). Unlike the job system, where an employer requires employees to work in a specific office from 9 AM to $5 \mathrm{PM}$ on weekdays, giggers do not need to work at a fixed place and during a fixed period. Instead, giggers provide products and services to clients worldwide through the network and mobile applications (Farrell \& Fiona, 2016; Jeffefy, 2017). This freedom allows organizations and individuals to connect with potential workers or clients anywhere in the world (Stefanot, 2016). For example, property (service) sharing platforms such as eBay and Airbnb link potential customers to sellers who are willing to lease their assets or sell their goods. Uber, TaskRabbit, and other labor-sharing platforms link possible customers to temporary workers (Farrell \& Fiona, 2016).

In summary, the essence of remote cooperation is organizations' loss of control and laborers' gain of control over the workplace. To a certain extent, both parties are beneficiaries. On the one hand, workers have the right to choose their own workplace, bringing considerable convenience to them while improving their work satisfaction and production efficiency. On the other hand, companies do not need to provide a workplace, thereby saving operating costs and expanding the 
source of available labor force.

\section{Flexible working time}

Flexible working time means that independent workers have autonomy and control over their working hours, so that work becomes flexible and random, which is based on hours or even shorter periods of time (Yang, W.G., Zhang, C.G. \& Xin, X.L., 2018). Instead of working as employees, individuals can make use of the digital platform and mobile applications to choose their work and arrange their working schedule (Thomas, 2018; US Department of Labor, 2019). Workers decide to carry out a specific temporary task or project as a self-employed or independent contractor, indicating that after completing a project, the same project has no further work requirements from them (Thomas, 2018). These tasks and projects are "gigs." Giggers undertake temporary projects by competitive bidding. Usually, a platform will have corresponding customer "scoring" and evaluation mechanisms to assess the performance of giggers (Thompson, 2018; Atmore, 2017). Under the gig economy, no matter what type of work (driver, freelance artist, temporary CEO) giggers are engaged in, and whether acquired by themselves or a third party (e.g. labor dispatching company), one work task could be referred as a "gig," that belongs to non-standard employment (McGovern, M., 2017). During flexible working hours, only a short-term working relationship is established between giggers and customers, and giggers need to complete temporary tasks within a limited working time. Examples of such gigs are graphic design, online consultation, legal consultation, and ride sharing. Moreover, the working term is generally less than 12 months (unlike traditional employment) (McKinsey, 2016). Obviously, in traditional employment relations, employees have no right to control their working hours, whereas the flexibility of working hours under the gig economy is undoubtedly the embodiment of laborers' control over the working process. However, this flexibility could be a double-edged sword. On the one hand, it helps workers maintain their work-life balance, thereby improving their working enthusiasm and satisfaction. On the other hand, for giggers who are forced into the gig labor market because of unideal circumstances (e.g., in consideration of survival, supporting for their family members), the flexible working hours may drive them to overwork, which brings about problems in their health, safety, as well as the quality of their output (Lott, 2015).

Undoubtedly, job decomposition brings flexibility in employment, and companies shift from having control over traditional working process to control over performance results. On the one hand, workers have achieved self-control and self-management in the course of their work. These abilities effectively encourage their self-creation, self-realization, and subjective initiative, which improve productivity and efficiency of enterprises. On the other hand, enterprises' expenses on supervision and providing working places can be greatly reduced. However, job decomposition also 
increases the possibility of non-continuity in work. Unlike the labor market in traditional industrial economy, individuals and their services and commodities in the gig economy are diversified. Hence, customer's needs are highly personalized and specialized. The allocation of diverse and scarce resources is carried out in the matching process, which is the resource allocation mechanism of the matching market (Roth, A.E., 2016). During the industrial economy era, economists primarily focused on commodity markets, which are referred to as "matching markets." The so-called "matching" can be understood as a mutual choice process between people and specific things they want to acquire (Roth, A.E., 2016), achieved through a structured matching process (application, selection, and so on). In the matching market, price is not the only nor the primary mechanism of resource allocation, because it is designed to achieve efficient allocation of scarce resources, rather than homogeneous, universal, and massive resources. In the matching mechanism, without enough suppliers and demanders, market density cannot be guaranteed; hence, resource allocation or maintaining labor continuity would not be optimized. However, pointing out that excessive density will enhance the risk of "blockage" is necessary, which would negatively affect the efficiency of resource allocation. The reason is that the denser the market is, the wider the range of choices; thus, a long time is needed to make a choice during the matching process (Roth, A.E., 2016).

Therefore, on the one hand, the government should strengthen the construction of technological infrastructure in the matching market and establish efficient, fast, mobile, secure, and credible information infrastructure. On the other hand, the government should also strengthen the construction of relevant facilities within enterprises to ensure accuracy, immediacy, symmetry, and transparency in the information released by enterprises to let workers thoroughly understand workrelated information. In this way, despite blockages, the market can be operated efficiently. Moreover, the human resources in the gig economy can be optimally allocated. Hence, the possibility of alleviating and even solving the problem as giggers' "lack of continuity in work" will be greatly increased.

\subsection{Skillization and capitalization of workers}

The so-called "skillization of workers" means that workers acquire higher "skills," which is not the same as the separation of intelligence and physical strength in industrial production (Marx, K., 2013). In the gig economy, a platform and an organization select workers based on specific skills that they need (Yang, W.G., Zhang, C.G. and Xin, X.L., 2018). The World Development Report 2019 states that technology is a powerful driver of the skills needed to reshape work. On a global scale, developed and developing countries simultaneously face a decline in the demand for low-skilled workers, who are easy replaced in the labor market, and increasing demand for high-skilled, highlyadaptable, and highly-cognizant workforce (World Bank, 2018). According to the World Bank, from 
2000 to 2014, Bolivia's high-skilled work employment ratio increased by 8\%, and that of Ethiopia increased by $13 \%$. The rising trend is not only characterized by the replacement of low-skilled workers by high-skilled workers, but also by increasing requirements for working skills (World Bank, 2018). The skill-oriented gig model has a high demand for individual labor capacity. Giggers with high capacity have more rights to demand high salary, and more spare time for work-life balance (Mulcahy, 2017a). Most enterprises are "result oriented," that is to say, the final work output is the key performance indicator of workers; thus, having the suitable skills would be beneficial for workers to meet customer's needs in this economic model (Mulcahy, 2017a; Frost, 2017). The demand for skills in the gig economy departs from the tradition of treating academic qualifications and certificates as the single evaluation standard, which has brought diversified human capital to enterprises and stimulated the subjective initiative of workers to develop their own skills.

"Capitalization of workers" means that a laborer, no longer a proletarian in the traditional sense, has a certain surplus of property (real estate, gardens, and cars) after being converted into assets that meet the needs of a consumer in the gig market. Under the industrial economy, workers, as the "proletarian," have no ownership of production materials (Marx, K., 2013). Employers also deprive employees of production tools while terminating the employment relationship between employees and employers, because production tools are owned by employers. Therefore, this employment relationship is asymmetrical due to employers' private ownership of production materials (Kroszner, R. \& Putterman, L.G., 2015). However, in the gig economy, a large number of individuals have their own properties, which can be converted into assets, and then invested in the market to gain income. Unlike homogenous products in the traditional industrial economy, these assets exemplify "diversity and heterogeneity." For example, individuals with vacant houses and apartments can lease them for short-term rentals on Airbnb and Xiaozhu. Those with private cars can register on Uber and Didi to become ride sharing drivers. Those with private gardens can have their own gardens rented on YardShare.

The "skillization" of workers can save companies' training costs and subsequently reduce their expenses from the resignation of employees who were trained. However, individuals need to bear the expenses for skills development. Under the pressure of being eliminated, they need to constantly enrich and upgrade their skills to adapt to changing market needs, especially for groups with limited physical conditions. In addition, high-skilled people can gain more job opportunities through platforms in the gig economy. More job opportunities mean more sources of income, which can be used for their skills improvement, further increasing their potential of gaining more work opportunities in the market. However, groups with relatively low skills may face employment barriers in the gig economy, forming a "neo-binary society" caused by skill differentiation (Yang W.G. \& Zhou, N., 2017). 


\subsection{Integration of internal and external human capital}

In traditional employment relationships, companies focus on the use and development of internal workforce. During the industrialization period, enterprises depend on the scientific management model to continuously reduce the skill level of laborers through the division of labor, and maximize economic benefits by minimizing production costs (Taylor, F. W., 2013). Owing to the intensification of labor management conflicts, enterprises have introduced a human resource management strategy based on unitary theory, with the belief that employers and employees have common interests, and labor management conflicts are only temporary. With the help of strategies and techniques for interest integration, employers arrange mutual relations between employees and employers to gradually create identical interests (Taylor, F. W., 2013). In the process, workers' work satisfaction and self-value are greatly improved. As a result, improving the labor productivity of employees and the economic interests of enterprises are achieved (Taylor, F. W., 2013). Nevertheless, in the traditional employment relationship, regardless of measures are taken, an enterprise only targets internal labor resources.

In contrast, in the gig economy, platforms do not only focus on the use of internal human capital, but also on the integration and utilization of internal and external human resources to maximize their profits (Yang, W.G., Zhang, C.G. and Xin, X.L., 2018). Lobel (2017) indicates that the essence of the gig economy is a new mode of employment that uses external human resources through the Internet. "Similar to the people who used to set up stalls outside the central square of Mexico City, seeking working opportunities and doing small business, large number of giggers nowadays through the online platforms to search for and obtain temporary working opportunities which meet their needs" (Wordsworth, 2016). Unlike employees in formal employment, giggers primarily come from outside the platform. Giggers have their own set of skills and strengths, and are highly autonomous. They exercise great control over the content, amount, and the manner that they work. By measuring indicators such as relevant expenses, clients' needs, and time spent, giggers determine whether and how to work. These decisions can be changed at any time at their personal will (McKinsey, 2016). The integration of internal and external human capital enables enterprises to diversify their workforce, optimize the allocation of labor capital, and save their production costs and resources.

However, the use of external human capital also brings problems, as companies are used to focusing on internal workers and have limited experience in managing external labor. Hence, how to efficiently use and effectively manage external human capital have become new issues for platform enterprises. For instance, the working process of external personnel is not controlled by an enterprise; enterprises cannot effectively monitor tasks assigned to external personnel until the projects are finished. "Skill loyalty" and "profession loyalty" are the main characteristics of external personnel; thus, traditional "corporate loyalty" is uncommon among external workers. 


\subsection{Decentralization of corporate management}

The decentralization of enterprise management means that enterprises (under the gig economy), through advanced technologies, such as network platform, digital technology, and mobile applications, gradually break away from traditional bureaucracy. Decentralization creates platformized, clustered, and distributed management from the inside to the outside of enterprises. Torpey and Hogan (2016) also indicate that "the choice of independent and autonomous individuals to be self-employed workers is not a new phenomenon, whereas people become the giggers in the Internet era is a relatively new thing, since the establishment of links between the enterprise and the laborer is through the network and the mobile applications, which play a role as the media." Specifically, an enterprise purchases monetized and timed tasks (results) or assets from available labor or asset owners through the platform that charges laborers or asset providers and customers with corresponding fees and commissions (Hunt, Samman, Ille, \& Max, 2018). Internet and mobile applications connect giggers and clients, significantly reducing transaction costs (Atmor, 2017), which refer to "costs of discovering the relative price in the market" as Coase mentioned in The Nature of The Firm (Williamson, O.E., 1993). The most important goal of a successful market is to bring together market participants with trading needs, which help them capture the best opportunities from combined effects (Roth, A.E., 2016). The Internet and mobile applications have become effective platforms for this purpose. Through a platform, an individual gigger signs a temporary contract with a client for an independent task (Sanders \& Pattison, 2016). Widely used mobile applications Uber and TaskRabbit, which link ride sharing drivers, work with potential passengers through digital technology (Thomas, 2018). Compared with the traditional employment model of bureaucratic firms, a gigger provides assets and services according to demand in the digital market, and plays the role of a self-employed employee rather than a traditional employee (Wordsworth, 2016).

In the labor market of the gig economy, traditional formal employment relations have been replaced by the emerging "working relations," where enterprises and giggers enjoy "autonomy" and "flexibility." These key advantages are manifested in giggers' self-control and decision-making power over working hours and content (Atmore, 2017). Additionally, companies no longer need to provide social insurance, welfare, and benefits to workers (Thompson, 2018).

In Scientific Management Principles, Taylor advocated the use of promotion and other human resource management means to improve employees' satisfaction and loyalty, with the ultimate goal of the improvement of corporate profits (Taylor, F.W., 2013). However, management methods such as promotions only exist in bureaucratic enterprises with highly sophisticated and complex management processes. Promotions can effectively encourage productivity and improve the 
economic efficiency of enterprises under the scale production of industrial economy. In the gig economy, these complex processes will significantly reduce the management and production efficiency of enterprises, and limit the development speed of enterprises themselves. In the era of the Internet with diverse, ever-changing, and large-scale market demand, the decentralized enterprise management model can help employers save on management costs while improving operational and production efficiency. For the employees, the decentralized management model gives them control and autonomy over their working process, undoubtedly promoting their job satisfaction and self-realization. Nevertheless, decentralized management has drawbacks. For instance, platform enterprises are not obliged to provide social security, welfare, and allowances to giggers. This situation leaves a large number of low-skilled and low-earning giggers unprotected. In the long run, the absence of benefits provided to giggers is not conducive to the development of giggers and platform enterprises. In fact, this set-up even negatively influences the development and stability of the entire society. However, not all giggers need such protection from enterprises because social security may not be highly significant for high-skilled and high-income groups. Without control on working processes from top management, this "bottom-up" type of control will most likely lose its effectiveness and even stagnate. In the absence of high-level leadership, lower-level workers will easily lose their motivation to work in the face of many other choices (Kelly, K., 2014).

\section{Conclusion}

Coase believed that in the industrial economy era, due to market uncertainty, information asymmetry, taxation and policies, the discovery of relative prices resulted in huge costs. As a result, the efficiency of resource allocation could not be effectively utilized. Individual laborers needed to coordinate with one another to save on transaction costs, increase profit margins and production efficiency; hence, firms emerged. Traditional firms were a resource distribution mechanism, taken as substitutes to the price mechanism (but we hold the two mutually complementary and coexisting). Coase theorem is based on a series of premises and assumptions of neoclassical economics. The theory regards a labor as a commodity and production factor, a worker is a rational economic man who does not have heterogeneity and pursues the maximization of his self-interest, and the division of labor becomes increasingly complex. Moreover, in the second industrial revolution, the invention and use of electrical appliances effectively promoted industrial scale production.

In the digital economy, with the unbelievably rapid development of information technology, and the birth and popularization of the Internet, social, political, economic, and cultural conditions have experienced tremendous transformation. The gig economy based on the digital platform and mobile applications has become one of the most notable emerging economy modes in recent years. Similar to the meaning and function of "firms", the gig economy is considered a new mechanism to 
effectively save costs, improve efficiency, and realize resource allocation, coexisting with the firm and price mechanism. Specifically, the gig economy has the following four characteristics. First, traditional jobs are gradually decomposed into small pieces (tasks or projects), accompanied by the remote cooperation between platform enterprises and giggers, as well flexible working hours. Second, unlike laborers who are "proletarianized" in the industrial economy, giggers generally have certain skills or assets, which are prominently diversified and personalized. Third, corporate management has moved from focusing only on the internal labor market in traditional employment to taking into account the internal and external labor market. In this integration, an enterprise maximizes internal and external human capital to achieve optimal resource allocation. Finally, management is decentralized and "platformized," in which enterprises end up "aggregating a large number of individual functions to form wisdom" through the Internet (Kelly, K., 2014).

As Kevin Kelly (2014) mentioned in New Rules for the New Economy: "our social mechanisms, especially mechanisms of the new economy, will gradually obey the logic of the network." The gig economy is seen as a type of newly emerging economic mechanism, in which the "network logic" is deeply embedded, and the role of the Internet is undoubtedly crucial, directly affecting its effectiveness in resource allocation functions. However, the construction and use of the network are immature and face many problems.

The first challenge is how to guarantee market density. Proficient use of the network and mobile applications has a certain threshold, leading to limited participation of some groups, such as the elderly and the poorly-educated. As a result, the density of the giggers' labor market cannot be guaranteed under certain circumstances. The criterion for measuring the success of a market is its ability to gather market participants who are willing to trade to achieve "market density." By achieving a certain level of market density, participants are able to gain "excellent transaction opportunities." Therefore, prioritizing the construction of the network and continually simplifying the user interface is necessary. Excellent user experiences mean that people can participate in the gig economy so that the "density" of the giggers' labor market will be finally guaranteed (Roth, A.E., 2016).

The second challenge is dealing with market "blockage." A dense market is not resistant to "blocking" problem. Over-density leads to poor operation; the denser the market is, the wider range of choices become available. Therefore, market participants will spend more time on evaluating, selecting, and completing a transaction (Roth, A.E., 2016). Hence, establishing and improving participants' preference prediction function in the platform digital processing center is necessary, so that the preference information generated can be used by participants to make decisions faster and finally avoid market blockage.

The third challenge is related to how to ensure network security. Insufficient network security 
absolutely brings negative effects on market credibility in the gig economy. Ensuring market security is a long-standing issue that the market needs to address especially in the gig economy. Only by making participants feel safe can their trust be increased and their participation in the market be ensured. People in the gig economy are often unfamiliar or strangers to one another; hence, the imperfect security and privacy make trust difficult for them. Participants who lack trust are reluctant to disclose their relevant information. Therefore, market efficiency will be greatly reduced and may even become ineffective. For example, platforms such as eBay and FreeMarket are susceptible to such effects during their operation. FreeMarket is an auction platform, where if a supplier participating in an auction refuses to disclose the routine discount to his competitor, then the auction will not proceed smoothly (Roth, A.E., 2016). Therefore, the government and enterprises should urgently strengthen the construction of network information security and the privacy protection of users. By doing so, trust among giggers and stickiness of participants in the gig economy will be achieved, as well as the health and stability of the market.

Last but not the least, the problem of the classification of giggers exists. The classification of workers will directly influence the relevant labor security, rights and obligations, because it is the basis for solving legal problems. In practice, the Opinion Letter issued by the US Department of Labor in April 2019 based on six factors ${ }^{2}$ to determine service providers for the platform enterprises (giggers) belong to independent contractors, but not employees (US Department of Labor, 2019).

In conclusion, the gig economy, as a newly-emerging resource allocation mechanism in the digital age, has various advantages and corresponding problems. Thus, we provide suggestions for relevant policy makers and practitioners. First, China's laws and regulations about the confirmation of employment relations in the gig economy should be established and improved by learning from other countries.' China should break away from the "all-or-nothing" employment-oriented legal confirmation framework (Ding, X.D., 2018) to make a specialized framework for confirming the working relations between giggers and platforms. Second, based on the new confirmation, China's social security system for giggers should be established and improved. Enterprises and the government should collaborate to provide social security for the giggers who are in need. Third, the construction of infrastructure (information platforms, and networks) should be accelerated. Information transparency, liquidity, and forecast accuracy of the gig market should also be promoted to ensure market density and smoothness, with the aim of achieving work continuity for giggers.

\section{Reference:}

\footnotetext{
2 Six factors: the nature and degree of controls from potential employers; the permanency of the relationship between potential employers and workers; the amount of workers' investment in facilities, equipment, and so on; the amount of skill, initiative, judgement, foresight required for the service; workers' opportunities for profit or loss; the extent of integration of workers' service into potential employers' business.
} 
1. Atmore, E. C..(2017). Killing the goose that laid the golden egg: Outdated Employment Laws Are Destroying the Gig Economy. Minnesota Law Review, 102 (2), 887-922.

2. Board of governors of the federal reserve system. (2017).The "gig" economy: Implications of the growth of contingent work (Board of governors of the federal reserve system report). Retrieved from https://www.federalreserve.gov/newsevents/speech /brainard20161117a.htm.

3. Canada Advisory Council on Economic Growth.(2017).Building a Highly Skilled and Resilient Canadian Workforce Through the Futureskills Lab (Government of Canada research paper), retrieved from https://www.budget.gc.ca/aceg-ccce/pdf/skills-competenceseng.pdf.

4. Ding Xiaodong.(2018).New thinking on the platform revolution, gig economy and labor law (Chinese). Global Law Review, 4, 87-98.

5. European Commission.(2016). The Future of Work--Skills and Resilience for a World of Change(research paper), retrieved from http://ec.europa.eu/epsc/publications/strategicnotes/future-work en.

6. Farrell, D. \& Fiona, G..(2016). Paychecks, paydays, and the online platform economy (Reserch report). Retrieved from https://www.jpmorganchase.com/corporate/institute/document/jpmc-institute-volatility-2report.pdf.

7. Frost, J..(2017). Uber and the Gig Economy: Can the Legal World Keep Up? Scitech Lawyer, 7, 4-7.

8. Government of Canada.(2016).Understanding the Realities:Interim Report of the Expert Panel on Youth Employment(Government of Canada research paper), retrieved from https://www.canada.ca/en/employment-social-development/corporate/youth-expertpanel/interim-report.html.

9. Hunt, A., Samman, E., Ille, D., \& Max, H.. (2018). The gig economy in complex refugee situations. Forced Migration Review, 58, 47-49

10. IMF.(2016). Role of Business in Supporting a More Inclusive Global Economy(research paper), retrieved from IMF http://www.imf.org/en/news/articles/2016/10/10/sp101016-therole-of-business-in-supporting-a-more-inclusive-global-economy.

11. Kelly, Kevin.(2014). New Rules for the New Economy (Chinese) (Liu Zhongtao et al., trans.) Beijing: Publishing House of Electronics Industry.

12. Kroszner, Randy and Putterman, Louis G.(2015). The economic nature of the firm(Chinese) (Sun Jingwei, trans.). Shanghai: Truth \& Wisdom Press, Shanghai People's Publishing House .

13. Lobel, O.. (2017). The gig economy \& the future of employment and labor law. University of 
San Francisco Law Review, 51(1), 51-73.

14. Lott, Y..(2015). Working-time flexibility and autonomy: A European perspective on time adequacy. European Journal of Industrial Relations, 21(3), 259-274.

15. Marx, Karl.(2013). Capital (Chinese)(He Xiaohe trans. ).Chongqing: Chongqing Press.

16. McGovern, Marion.(2017). Thriving in the Gig Economy (Chinese) (Qiu muonan, tans.). Beijing: Citic Press Corporation.

17. Mckinsey. (2016). Independent work: Choice, necessity, and the gig economy (Mckinsey \& Company Research Report). Retrieved from https://www.mckinsey.com/globalthemes/employment-and-growth/independent-work-choice-necessity-and-the-gig-economy.

18. Mckinsey.(2016a).Exploding Myths About the Gig Economy (Mckinsey \& Company research report), retrieved Nov 20, 2017, from https://www.mckinsey.com/mgi/overview/in-thenews/exploding- myths-about-the-gig-economy.

19. Mulcahy, D..(2017). Will the Gig Economy Make the Office Obsolete? Harvard Business Review, 3, 2-4.

20. Mulcathy, D..(2017a). The Gig Economy. New York: American Management Association.

21. Office of Tax Simplification. (2016).OTS Gig Economy Summary Paper (Office of Tax Simplification research paper), retrieved from https:/www.gov.uk/government/uploads/system/uploads/attachment_data/file/573499/OTS gig_economy summary final_Nov_16.pdf.

22. Rosen, D.J..(2016). The gig economy and career pathways (Literacy Information and Communication System Research Report). Retrieved from https://community.lincs.ed.gov/discussion/gig-economy-and-career-pathways.

23. Roth, Alvin E. (2016). Who gets what - and why the new economics of matchmaking and market design. New York: Eamon Dolan / Houghton Mifflin Harcourt.

24. Sanders, D.E. \& Pattison, P.. (2016).Worker characterization in a gig economy viewed through an uber centric lens. Southern Law Journal, 26(2), 297-320.

25. Stefanot, D.S.. (2016). The rise of the just-in-time workforce: On-Demand work, crowdwork, and labor protection in the gig-economy. Comparative Labor Law \& Policy Journal , 37(3), 471-504.

26. Stephany, Alex. (2016). The business of sharing making it in the new sharing economy (Chinese) (Hao Juanjuan et al., trans.). Beijing: China Renmin University Press.

27. Smith, Adam.(2016). An inquiry into the nature and causes of the wealth of nations (Chinese)(Chen Xing, trans.).Beijing: Beijing United Publishing Company.

28. Taylor, Frederick Winslow.(2013). The principles of scientific management(Chinese) (Ma, Fengcai trans.). Beijing: Mechanical industry press. 
29. Tepper, S.J..(2016). What Does it Mean to Sustain a Career in the Gig Economy?, retrieved July 23, 2017, from National Endowment of the Arts Web Site:

https://www.arts.gov/partnerships/creativity-connects/report/what-does-it-mean-to-sustain-acareer-in-the-gig-economy.

30. Texas Workforce Investment Council.(2017).Research Report: The Gig Economy in the U.S., retrieved from

https://gov.texas.gov/uploads/files/organization/twic/Gig_Economy_in_US_March_2017.pdf.

31. Thomas, K.D..(2018). Taxing the gig economy. University of Pennsylvania Law Review,166(6), 1415-1473.

32. Thompson, B.Y. (2018). Digital Nomads: Employment in the Online Gig Economy. Journal of Culture, Politics and Innovation, 1, 1-26.

33. Torpey, E. \& Hogan, A..(2016). Working in a Gig Economy. Retrieved July 18, 2017, from United States Department of Labor Web Site:

https://www.bls.gov/careeroutlook/2016/article/what-is-the-gig-economy.htm.

34. U.S. Department of Labor. (2019). Opinion letter-FLSA2019-6. Retrieved May 15, 2019, from United States Department of Labor Web Site: https://www.dol.gov/whd/opinion/FLSA/2019/2019_04_29_06_FLSA.pdf

35. Wang Qi, Wu Qingjun and Yang Weiguo. (2018). Research on the nature of employment on digital platform: Based on case study of P Car-Hailing Platform(Chinese). Human Resources Development of China, 35(8), 96-104.

36. Williamson, O.E.(1993). The nature of the firm : origins, evolution, and development. Oxford: Oxford University Press.

37. Wordsworth.(2016). Mind Your Language: Gig Economy. The Spectator, 7, 1-2.

38. World Bank. (2018). World Development Report 2019 (Research report). Retrieved from http://xueshu.baidu.com/s?wd=paperuri:(5f478acc32b900164ff18c0b9f0c8b01)\&filter=sc 1o ng sign\&sc ks para $=\mathrm{q} \% 3 \mathrm{DWorld}+$ Development + Report $+2019 \& \mathrm{tn}=\mathrm{SE}$ baiduxueshu clgje upa\&ie $=$ utf-, $8 \&$ sc us $=11076801037718669788$.

39. Yang Weiguo, Zhang Chenggang and Xin Xili.(2018). A study on digital economy paradigm and working relations revolution(Chinese). Journal of China University of Labor Relations, 5(32), 56-60.

40. Yang Weiguo and Zhouning. (2017). Sharing economy and new employment patterns (Chinese). Green book of population and labor No. 18. New economy New employment,8697. 